reaction favours the growth of yeasts and filiform acidophilous bacilli, and adhesion of the epithelial scales to each other. Once the condition begins the organisms are protected in the crypts between the filiform papillae, and by their fermentative power help to maintain the acidity of the mouth.

The case we report below yielded readily to a liquor potassae mouth wash. In other cases the lesion is said to disappear and recur in spite of treatment. In our view the essential treatment is to maintain an alkaline reaction in the mouth.

The patient was a man of $\mathbf{4 5}$, who had discovered a lesion on his tongue ten weeks before coming under observation. His tongue showed a triangular black hairy patch, the base at the circumvallate papillae and the sides a little distance from the margin and tip of the tongue. The hairs could be pushed in various directions with a spatula, but brisk scraping was necessary to remove them. They were longest at the centre and back of the lesion, where they measured up to three-quarters of an inch in length. The hairs were elastic, and stretched on attempting to pull them out. When removed the black colour was seen to occupy only the upper half of the hair, the remainder being white.

The patient was edentulous, but had good plates. He complained of a burning sensation over the tongue. He had rubbed off the growth once, and also stopped a bismuth mixture which he was taking for indigestion, without effect. After making the examination the growth was again briskly scraped away, and a liquor potassae and carbolic mouth wash prescribed. The patient reported that the lesion became gelatinous, and he scraped it away easily, so that it had disappeared a week later.

Pathological Findings.-Microscopically the hairs were not true hairs, but were composed of elongated masses of epithelial cells and scales. The pigment appeared as a diffuse brown coloration of the cells. The epithelial masses were covered on all sides with an enormous number of yeast cells, along with a Gram-positive filiform bacillus. Aerobic and anaerobic cultures on agar and 2 per cent. dextrose agar gave a growth of a few sarcinae and streptococci and very numerous colonies of a yeast and of a bacillus. The latter was finally identified as an acidophilus bacillus. It was non-pathogenic to guineapigs and rabbits. The yeast grew readily on dextrose agar, forming a white growth with no late pigment formation. Microscopically it showed round or oval forms, with sausageshaped cells in some fluid media. Repeated tests for ascospore formation by placing an actively growing culture on plaster-of-Paris blocks standing in distilled water were negative, nor were ascospores seen in old cultures on carrot, potato, etc. In this respect it is identical with the yeasts cbtained from cases of hairy tongue by Lucet, Guégan, and Green. ${ }^{8}$ It produced acid and gas in dextrose, saccharose, and levulose, but had no effect on maltose, mannite, or lactose. These fermentation reactions are identical with those obtained by Lucet and Guégan. The pathogenicity of the yeast for laboratory animals was as follows. Doses up to $2 \mathrm{c} . \mathrm{cm}$. of a saline suspension (strength 550 million per $1 \mathrm{c} . \mathrm{cm}$.) given intraperitoneally to guinea-pigs (five experiments) or subcutaneously (three experiments) caused a local suppuration which healed readily and did not cause a generalized infection. Tested on two mice and two rats $0.5 \mathrm{c} . \mathrm{cm}$. of this emulsion, given subcutaneously, was without effect. Three rabbits received intravenous injections of $0.5,1.5$, and $2 \mathrm{c.cm}$. respectively, and all survived.

\section{Comment on Pathological Findings}

From the morphology the yeast must be classed as a cryptococcus. It may be noted that had ascospores been found the yeast would correspond with certain of the common saccharomyces used in industry for brewing beer, etc. Hansen has shown that yeasts may lose their power of ascospore formation permanently if cultivated at a temperature of $32^{\circ}$ to $37^{\circ} \mathrm{C}$., and it seems likely that this cryptococcus is a saccharomyces which, owing to a long stay in the mouth, has become asporogenic. Yeasts are common inhabitants of the mouth and skin.
Greenbaum and Klauder found yeasts on the skin in thirty-nine out of 150 unselected cases. These were saccharomyces or cryptococcus, of the same types that they isolated from their cases of yeast dermatitis. An examination of swabs from the tongue in seventy patients chosen at random in the casualty department of the Liverpool Royal Infirmary revealed the presence of yeasts in thirtytwo, of which five showed mycelium formation (monilia).

\section{REFERENCES}

${ }^{1}$ Lake, R.: British Medical Journal, 1891, ii, 946.

2 Balfour-Graham, R.: Ibid., 1887, i, 61.

Hunt, M., and Roberts, L.: Liverpool Med. Chir. Journ., 1903, xxiii, 106.

${ }^{4}$ Catanei, A.: C. R. Soc. de Biol., 1925, xciii, 1492

Charpy, H.: Thèse de P'aris, 1904 (British Medical Association Library-literature)

${ }^{6}$ Barnard, H. M.: Clin. Joum., London, 1904, xxiv, 13.

"Heidingsfeld, M. L.: Journ., Amer. Med. Assoc., 1910, lv, 2117 (literature).

${ }^{8}$ Green, R.: Indian Med. Gazette, 1928, lxiii, 381.

\section{A CASE OF "BLACK TONGUE"}

$$
\text { BY }
$$

\section{H. MORTIMER WHARRY, F.R.C.S.}

SURGEON FOR DISEASES OF THE THROAT, NOSE, AND FAR, BOLINGBROKE HOSPITAL

After seeing several ordinary, or minor, cases, it is sometimes useful to describe an extreme case, which may throw some further light on a subject usually dismissed by the textbooks in one or two paragraphs.

\section{Report of Case}

The patient, a man aged 52, living in comfortable circumstances, came to see me complaining of chronic irritation of the throat and a cough which caused him continual annoyance, although it was not very serious. $\mathrm{He}$ had had this for eighteen months, and had been told that it was due to septic teeth, several of which he had had removed, but without any amelioration of the symptoms.

On examination I found an extensive pale brown spongy mass occupying the posterior half of his tongue. I removed this growth with a pair of forceps, and it came away in several long strips, leaving the tongue underneath looking approximately normal to the naked eye. The strips of growth were placed in a white dish and dried rapidly, assuming a dark purple colour, which was in marked contrast to the previous pale brown of the appearance noted when upon the dorsum of the tongue.

A fresh piece of growth was sent to the Laboratorics of Pathology and Public Health, where the membrane was reported to consist of a " budding yeast-like fungus" of the monilia type.

On culture the growth was extensive, and brown in colour, and the sugar reactions were those of the Monilia macroglossia, which is identical with the Cryptococcus linguae pilosae found in cases of black tongue.

\section{Commentary}

The following points emerge from consideration of this extensive and long-standing case:

1. Black tongue may spread over the posterior third of the tongue, and is not confined to localized patches anterior to the circumvallate papillae.

2. The dark colour is caused by the fungus, and not necessarily by any changes in the papillae of the tongue itself.

3. The disease may be of long standing, and yet not cause any hypertrophy of the papillae, either filiform or circumvallate.

4. The hypertrophy of the filiform papillae, so often noticed before, is probably due to continuous irritation of the tongue at one particular spot where the fungus has taken a firm hold.

5. The growth of the fungus is the primary condition, and may exist without any lingual hypertrophy. 